Acta Universitatis Wratislaviensis No 3836

Anglica Wratislaviensia LVI, Wrocław 2018

DOI: $10.19195 / 0301-7966.56 .15$

\author{
Marla Perkins \\ ORCID: 0000-0003-4146-9932 \\ Independent Scholar \\ dr.marla.perkins@gmail.com
}

\title{
Conceptualizing Measurement and Quantification in Hobongan: An Overview of the Lexicon and Uses
}

\begin{abstract}
In this survey of the Hobongan lexical items, I identify patterns in the Hobongan understanding of measurement and quantification. In Hobongan, there are many terms for measurements, usually some form of estimation. Hobongan has a four-based counting system, and those forms are used to estimate (one is one or hardly any, and four is quite a lot) and function as articles in sentences. Hobongan has also borrowed more counting terms and has the lexical items necessary for precise quantification, but those quantifications are used primarily within certain domains, such as determining what they should be paid for gold that has been mined or what should be paid in fines after legal judgments. Estimates of measurements can reference common objects, such as segments of bamboo or the height of a standing human. Perhaps the richest aspect of the system is that of measurement, in which terms that provide ways to estimate temperatures, magnitudes, and other amounts can indicate the ways in which the Hobongan make estimates from contextual information and apply the terms in use. In Hobongan, measurements in the form of estimates are primary and obligatory. Quantification with numbers is exclusively a type of symbolic and symbolized reasoning that must be combined with the estimate terms in order to be acceptable and functional.
\end{abstract}

Keywords: Hobongan, Hovongan, Austronesian, lexicon, lexical semantics, measurement, quantification

\section{Introduction}

This study is a lexical-semantic survey of the lexical items of measurement and quantification in Hobongan. Because of its limited size, the inventory of terms for measurement and quantification can be a unique topic within which to examine cultural and linguistic aspects of the Hobongan weltanschauung as it is exemplified within conceptual domains of measurement and quantification. Hobongan has three main conceptual domains for measurement: closed-class elements that are used 
similarly to articles to indicate broad estimates of quantity; a category for counting that was closed class but that has been opened to include borrowings for larger numbers; and measurement terms, in which conceptualized quantities are made lexically concrete by referring to various aspects of external reality.

Hobongan measurement terms are sometimes used in combination with counting terms to create quantifications of external reality that might be considered more objective, but the overall system in Hobongan measurement relies on scalar implicatures and contextual information about amounts, volumes, etc., that are subjective. The recognition of subjective components in quantification makes Hobongan patterns of measurement and quantification an integral part of the language and culture and can indicate ways in which the Hobongan interact with and evaluate the world in which they live.

\subsection{Method}

The study is based on field work conducted in 2012-2015 on Hobongan. Hobongan is an Austronesian language spoken by approximately two thousand people on the island of Borneo. The type of field work conducted for this study is generally known as Community-Based Language Research. It has been described (Czaykowska-Higgins 2009) as language research conducted on a language or languages, for the language community, with the language community, and by the language community. In other words, the linguist(s) involved are active participants as opposed to external observers (Dimmendaal 2001), and native speakers are integral parts of the process, which leads toward some benefit to the community. I participated in the daily life of the Hobongan in order to observe the ways in which the Hobongan use concepts and measurements. All of the example sentences included in this study were contributed by native speakers.

My field work has been immeasurably enhanced by the contributions of Rachel Searcy, a missionary who works among the Hobongan toward a translation of the Bible. She lives among the Hobongan and is familiar with detailed aspects of both the language and the culture. She has been willing to share her insights and information freely; this analysis is made freely available to Searcy and the Hobongan because it is part of the documentation that the Hobongan can use to gain minority rights under Indonesian law.

\subsection{Theoretical Grounding}

The research questions for this study include: What are the Hobongan lexical elements of quantification and measurement? How is the lexical inventory used? In what ways do these lexical elements and their uses reveal aspects of the Hobongan weltanschauung? In order to answer these questions as completely as possible, I 
rely on Nexus Theory (Perkins 2017). Nexus Theory approach to examining various types of information in languages, starting with discourses (unites of language that are larger than the sentence) and examining the ways in which discourse and real-world contexts affect syntax and semantics in use. This study is primarily a study of lexical semantics but includes elements of syntax, discourse, and pragmatics, as necessary to examine the ways in which the semantics of the lexical items are used, applied, and modified. This material is therefore qualitative rather than quantitative, with the goal of conducting basic research that provides requisite foundations for future research.

\subsection{Important terms}

For the purposes of this study, 'conceptualization' includes all of the ideas that people have about their worlds and about how their worlds work. Conceptualization is culturally constrained information about people's weltanschauungs that is revealed through linguistic information. Information can be considered data points, which can be analyzed at different levels as required for the domain being analyzed. For example, if one is looking at sentences, lexical categories might be useful as data points.

Because this is an analysis of information contained in lexical items, the semantically required definitions of those terms and the pragmatic flexibility of those terms in use are the data points. Semantic information is information that is necessarily definitional to lexical items; semantic information cannot be defeased by context. Pragmatic information is information that is provided by the interactions among structures and lexical items and broader contexts. Pragmatic information is usually not stated but must be inferred in order to derive meaning from language in use. Pragmatic information can be defeased or otherwise changed by different contexts. Sentential syntactic information is information that links words and contexts at the sentence level. A strategy is a linguistically and culturally available way to manage various kinds of information. Because strategies are linguistically and culturally delineated, they are contained in the overall conceptualizations or ideas that people have about their world's and about how their worlds work.

For the purposes of this study, 'measurement' is the activity of noting or using concepts about amount, volume, etc., and 'quantification' is one strategy for making measurements. For example, a large herd of animals might be evaluated simply as 'large'; 'large', in this case, is an evaluation and a measurement, but is not quantified. Quantification would require that a number be assigned, for example, three thousand. 


\subsection{Introduction to the language and community}

Hobongan is an Austronesian language, according to the categorization provided by a survey of the languages of Borneo (Simons and Fennig 2017; Hammarström et al. 2017; Sellato and Sercombe 2007). When the language was first catalogued, it was called Hovongan, which is inaccurate with regard to the phonology of the language. In Hobongan, a /b/ intervocalically is realized as a voiced bilabial fricative $[\beta]$. The language was catalogued officially with the inaccuracy, and although attempts have been made to update the name of the language, the correction has thus far been refused. The language is spoken by three generations of people, despite pressures on the Hobongan people and language to conform to the majority language and culture. Children are educated almost entirely in the national language, Bahasa Indonesian, and trade takes place in Putussibau, where Bahasa Indonesian and another trade language, Malayu, are used. Hobongan is the dominant language in the area along the Kapuas River where the Hobongan live, which provides some protection to the language by providing status for Hobongan; when trade happens among different groups of people in the area, Hobongan is the preferred language. Typologically, Hobongan is primarily SVO and analytic, although there are some instances of productive inflectional prefixes and some evidence of historical compounds that are no longer productive.

\subsection{Identifying elements of quantification and measurement}

Measurement Theory is a branch of philosophy of mathematics that examines how numbers are assigned, what kinds of things can be quantified, what types of quantification there are, and how various quantifications relate to one another (Kranz et al. 1971).

According to Stevens (1957), there are different types of measurement, also known as different types of scale. These kinds of measurement or scale have been assumed to be universal, and in their broadest interpretation, they probably are. However, the cognitive uses of the broad outlines can vary enormously across languages and individuals.

First, there are ordinals, in which order matters. However, the distance between the items being compared (e.g., $1^{\text {st }}, 2^{\text {nd }}, 3^{\text {rd }}$ places in a race) is not specified. In this type of measurement, only the measurement itself can be compared, not relationships between or among the items.

Second, there are interval scales, in which the distance between the items being compared is consistent, such as temperatures measured in Celsius or Fahrenheit. With this type of measurement, relationships between measurements can be compared. Interval scales include the information of both order and interval.

Third, there are ratio scales, in which the distance between items being compared is consistent, and there is a non-arbitrary zero, such as in the Kelvin scale. A 
non-arbitrary zero means that there is nothing, relative to what is being measured. In temperature, the energy that is being measured by temperature could, in theory, be reduced to none; that is absolute zero. By contrast, Fahrenheit's zero is the temperature at which water freezes at sea level; another zero could be chosen, and in fact was: that is the Celsius scale.

Stevens does not include cardinal numbers in his 1957 work, but with regard to languages, it is important to understand all of the elements available by which people indicate their uses of the ordinal, interval, and ratio scales, which is why this study begins with cardinal numbers. Further, these basic elements are foundational, and not necessarily instantiated in the same ways in different languages; Solt (2016) notes ways in which these different scales can be used to help clarify the semantic content of quantificational expressions, such as 'most' and 'more than half', and the scales will be used to help clarify the elements of Hobongan quantification, while noting ways in which Hobongan uses these scales in language-specific ways.

In addition, quantification and measurement can be distinguished from one another. In Hobongan, estimates such as 'many' are used frequently, and quantification is available but not always used. Even with measurement, quantification, and scales available as a starting set of concepts, it is not always easy to determine what should or should not be included in a survey of elements of measurement. For example, some terms have an inherent element of measurement but not necessarily quantification, and Stevens does not include this phenomenon in the analysis. For example, 'hill' and 'mountain' are generally taken to be the smaller and larger versions of a protruding feature, even if these terms can be used for different geographical scales. For example, in the Texas hill country, a feature that is at its highest point six hundred thirty-two feet $(193 \mathrm{~m})$ above sea level is Cusseta Mountain, and in Denver, Colorado, where the average ground level is a little over five thousand feet above sea level $(1600 \mathrm{~m})$, geographic indentations can have a greater elevation than some mountains in Texas.

Further, some options for inclusion might be categorized into more than one category. Because this is primarily a lexical semantic study, I have divided categories based on broad semantic content of measurement terms, such as topology and count or non-count items. The semantics of the terms are then compared contrasted with the ways those terms instantiate the presumably universal aspects of measurement theory. Many of the terms might be categorized according to lexical category, but because lexical categories in Austronesian languages are notoriously flexible (Van Lier 2016), any indication of lexical category in basic definitions of the terms analyzed in this study should not be taken as a commitment to any lexical category. 


\section{Measurement and quantification in Hobongan}

Hobongan examples in this paper are given according to the Hobongan writing system. Examples labeled 'HH' are from a set of Hamun Hamang stories, oral tales that have been collected and developed into literacy materials by Searcy. Examples labeled 'LT' are from the translation of the Gospel of Luke; it might not be ideal to use a translated work for linguistic examples, but doing so has a long history in linguistic description because a translation might be all that is left of a language or all of the discourse that was published. In addition, in this case, the Hobongan are actively involved in the translation; by the time the translation process is complete, 6-10 people have agreed that what is included in the translation is the best possible way to express the material in Hobongan; nevertheless, the ideas are not Hobongan, which means that the examples should be taken as examples of uses of terms and expressions, not as material that reveals Hobongan ideas.

In any paper of a finite length, it is impossible to include every example that might be useful or interesting, and the examples here were chosen to show how the terms in the categories are typically used.

\subsection{Counting and Ordinals}

Hobongan originally had a base-four system of counting. Counting is not much of an activity in Hobongan; children learn to count in school rather than as a fun activity that parents do with their children. Instead, the four Hobongan cardinal numbers are used as estimates of quantity on countable nouns.

The terms are as follows: $c i q$ (one when counting; $c i$ (when used as an article)); $d u o$ (two); tou (three); pat (four). $C i$ is usually one, but duo can be a couple or a few, and tou is an estimate that is more than two or a few (many), and pat is a lot. There is also an idiom for 'more than one can count' (kitaq meqe), but it is not frequently used.

$\begin{array}{lllllllll}\text { Luo } & \text { moq } & \text { so } & \text { nataq } & \text { a } & \text { sokala } & \text { buun } & \text { baba } & \text { petet nan } \\ \text { dead.leaves } & \text { and } & 3^{\text {rd }} \text {.sg.fm } & \text { cut.once } & \text { affect } & \text { all } & \text { hair } & \text { mouth } & \text { fish }\end{array}$

$\begin{array}{lllllll}\text { lua } & \text { moq } & \text { paqasaq } & \text { ho } & \text { ci } & \text { piso } & \text { nen. } \\ \text { past } & \text { and } & \text { put.in } & 3^{\text {rd }} \text {.sg.nonhuman } & \text { one } & \text { small. bag } & \text { EMPH }\end{array}$

'She cut the dead leaves, which changed all of the fish' whiskers, and put it in the small bag.' $\mathrm{HH}$

$\begin{array}{lcllllll}\begin{array}{l}\text { Jadi } \\ \text { then }\end{array} & \begin{array}{l}\text { luhang } \\ \text { middle }\end{array} & \begin{array}{l}\text { Yesus } \\ \text { Jesus }\end{array} & \begin{array}{l}\text { kan } \\ \text { give }\end{array} & \begin{array}{l}\text { tobara } \\ \text { teaching }\end{array} & \begin{array}{l}\text { joq } \\ \text { FOC }\end{array} \text { labiq } & \\ \text { arrive } & \\ \text { ko } & \text { mono } & \text { hitou } & \text { pat } & \text { koring } & \text { ni } & \text { sangketang } \\ \text { result } & \text { present.time } & 3^{\text {rd }} \text {.trial } & \text { four } & \text { body } & \text { that } & \text { companion }\end{array}$




$\begin{array}{lllllll}\text { itet } & \text { abak } & \text { hitou } & \text { moq } & \text { beong } & \text { itet } & \text { anya } \\ \text { take } & \text { close.friend } & 3^{\text {rd }} \text {.trial } & \text { and } & \text { want } & \text { take } & 3^{\text {rd }} \text {.sg.masc }\end{array}$

$\begin{array}{lll}\text { ce } & \text { nao } & \text { Yesus. } \\ \text { away.from.river } & \text { reach } & \text { Jesus }\end{array}$

'While Jesus was giving teaching, some people came who were carrying their companion and wanted to bring him to Jesus.' Luke 5:18, LT

In the first example, the use of a quantification term, $c i$, is used similarly to an article. Because there is only one bag, and because the bag was available in the discourse prior to this example, the definite article best represents its meaning in that sentence. In the second sentence, the trial pronoun (three people) and the estimate provided by pat interact so that the estimate is given and the more precise constraints of the pronominal system is not taken too literally.

Hobongan has acquired a full system for counting, which is used primarily to track and measure gold weights and prices, and sometimes other prices or people's ages, when birthdates are known. Otherwise, the Hobongan tend to use their four counting terms as estimates, in parallel with the grammatical requirements of the language. If something being estimated is a great deal more than more (pat), the Hobongan seem to pick any large number that might cover the quantity, similarly to English 'gazillion'.

\subsection{Plexity}

According to Talmy (2001: 48), plexity is the property of terms that gathers items into groups or separates items from a category or group. As a measurement, plexity makes a distinction between singularity and plurality; it changes the countability of items, grouping into singulars or dividing into plurals.

The terms are as follows: daang (makes a singular group from any collection of items); hikot (each, emphasizing parts of a whole); kobaqu (a large number, many); kobihan (a large quantity, a unit); kube (question word for quantity: how many?); lagiq (again: plexity for events); loe (one at a time); milang (every, space/time); mitak (separate a little from a larger amount, euphemism for death); ngomok (measure by seaparation); ngororuon (disappearing one at a time until gone); ngorotobirong (hang one at a time); takaron (section or part).

Moq so nguku a ukeq so moq seou ko poqo so pano lagiq.

There are also some phrasal expressions: kite dumit (a little bit for each person, from kite, a pinch); kube lekot (question phrase for iteration: how many times?); leou-leou (one and only).

$\begin{array}{lllllll}\text { Ure } & \text { ko } & \text { tika } & \text { ko } & \text { lohaq } & \text { nyuap } & \text { joq } \\ \text { Do } & 2^{\text {nd }} \cdot \text { sg/result } & \text { awake } & \text { post.descript } & \text { light } & \text { morning } & \text { FOC }\end{array}$




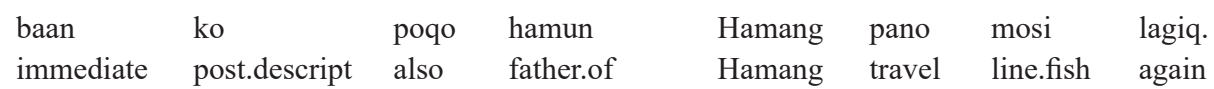

'After that, he woke up in the morning and immediately Hamun Hamang went out to fish again'. HH

$\begin{array}{lllllll}\text { Moq } & \text { anya } & \text { nacong } & \text { hiro } & \text { humoq } & \text { ho } & \text { hikot } \\ \text { And } & 3^{\text {rd }} \cdot \text { sg.masc } & \text { order } & 3^{\text {rd }} \cdot \mathrm{pl} & \text { drink } & 3^{\text {rd }} \cdot \text { sg.nonhuman } & \text { each } \\ \text { koring } & \text { hiro } & & & & & \\ \text { body } & 3^{\text {rd }} \cdot \mathrm{pl} & & & & & \end{array}$

'And he ordered them each to drink from his body for them'. Luke 22:20, LT

In these examples, two plexities are exemplified. In the first, the potential singular group is split into individuals, who are conceptualized as plural; this is Hobongan plexity for things. In the second example, the term lagiq affects the plexity of an event, creating a potential series of events, in which this is the second instance of the event.

\subsection{Topology}

Topological terms are typically magnitude neutral (Talmy 2000: 26), shape neutral (Talmy 2000: 27), closure neutral (Talmy 2000: 30), discontinuity neutral (Talmy 2000: 30), bulk neutral (Talmy 2000: 31), token neutral (Talmy 2000: 32), and substance neutral (Talmy 2000: 32). Topological terms in language describe geometric properties that are conceptualized at their most abstract, not with regard to specific physical properties. Geometric properties that are abstracted away from physical properties might seem odd candidates for a consideration of measurement, but each of these terms has semantic content that is inherently a type of measure, such as describing a full circle, or size properties that are used as comparisons and contrasts with size of other items in a context.

There are two categories of topological terms in Hobongan. The first contains descriptors and actions than can be applied flexibly and that rely on concrete domains more transparently than abstractions often do. ${ }^{1}$ The second category contains topological terms that are used as qualities and are abstracted away from any definite reference to a concrete domain.

${ }^{1}$ It might be considered odd to include descriptors and actions in the same category, but in Hobongan, there is not a clear syntactic distinction between verbal elements and modifier elements; terms shift between and among syntactic functions, as has been noted for Austronesian languages (Van Lier 2016). Because this is primarily a semantic description, the apparent syntactic distinctions are backgrounded. An anonymous reviewer has suggested that the syntactic distinctions that do arise, for topology, plexity, etc., would be an interesting topic for future research, and indeed it would, but it is beyond the scope of the current study. 


\section{3a. Topological descriptors and actions}

In this first category, the measurements rely on concrete domains such as people and plants for their semantic content. This might be used to suggest that the domain is not substance neutral, but the terms are extended beyond their physical groundings, which gives them neutrality. In those terms such as kotolusiq that apply primarily to a single substance, the question remains about substance neutrality, with the possibility that the usual use is not necessary but an example of colocation. The terms are as follows: cangkoko (turn all the way around, lit. kill by wringing neck); cutang (tall, as a person standing); daba (wide); dahom (deep, relative to a standing person); dibuq (short, relative to a person standing); dimit (small); dokop (low); dopo (arm's length); dumit (little); hiuq (high in altitude, loud sound); hoco (long); ira (lower down/under); kaang (thin, relative to fruit); kape (thick, of any material, but especially of wood); kolongeang (really long) kotolusiq (thin meat on a fruit seed); labeng (wide); loa (length from knuckle to index fingertip); lokin (close, distance/time); luhang (middle, space/time); mosut (make larger); mисоq (size of holes in a fish net); nacap (cut something long with one stroke); neqe (shallow, can stand up in); ngorosopukoi (long and narrow, usually of cassava); ngorumit (tiny, small); nyipi (thin); nyokamat (to do something small, or for a short time); nyopotan (to do something big, or for a long time); soripong (even in length); tami (narrow); tolocong (long and narrow); uhat (anything long and narrow; the difference between this and tolocong is currently unknown)

There are also some phrases: koqung maam (middle of the night: koqung round object, maam — night, conceptualized as an area); taqang рописи (measurement from index finger to thumb); uso sikun (measure from hand to elbow)

True to the closed-class nature of many topological items, there are a couple of prefixes: koko- (extension: more and more, or less and less); kono- (increase).

\begin{tabular}{|c|c|c|c|c|c|c|c|}
\hline $\begin{array}{l}\text { "Na," } \\
\text { then }\end{array}$ & $\begin{array}{l}\text { keo } \\
\text { say }\end{array}$ & $\begin{array}{l}\text { so, } \\
3^{\text {rd }} \text {.sg.fem }\end{array}$ & $\begin{array}{l}\text { "cutang } \\
\text { tall }\end{array}$ & $\begin{array}{l}\text { cutang } \\
\text { tall }\end{array}$ & $\begin{array}{l}\text { kom } \\
2^{\text {nd }} \cdot p l\end{array}$ & $\begin{array}{l}\text { itet } \\
\text { INST }\end{array}$ & $\begin{array}{l}\text { ku," } \\
1^{\text {st }} \cdot s g\end{array}$ \\
\hline 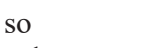 & jo & hiro & cutang, & & & & \\
\hline $3^{\text {rd }}$.sg.fem & $\mathrm{F}$ & $3^{\text {rd }} \cdot \mathrm{pl}$ & tall & & & & \\
\hline
\end{tabular}

'Then,” she said, "you were very tall to me," she said about his height'. HH

As is expected from topological terms, they are often used with regard to subjective evaluations of the items being described. The character being described in this example is cutang because he is higher from a conceptualized ground plane than the speaker. This example also provides instances of emphasis (the repeated cutang emphasizes and extends the tallness), and abstraction (the last cutang is better translated 'height' because it refers to the quality of being tall, rather than to an instance). 
In this topological category, there are a number of semantic minimal pairs or triplets, falling into a number of categories; some rely on dimensional distinctions (x-axis vs. z-axis: daba/labeng and kape), some on orientation distinctions such as whether measurement begins upward or downward along a y-axis from an $\mathrm{x}$-axis (dahom and neqe), some on distinctions between materials (kaang and nyapi), some on the magnitude conceptualized significance (nyokamat and nyopotan), some on combinations of two dimensions (limitations along the $\mathrm{x}$-axis and the $\mathrm{y}$-axis, as in tolocong and uhat, vs. limitations only along the y-axis, as in tami), and some on conceptualizations of relative magnitude that access scalar implicatures for applicability (cutang, dibuq). Because of length limitations, there is not room to multiply examples as might be wished, but here is one with dibuq, to contrast with cutang: $\begin{array}{llllllll}\text { Ho } & \text { mono } & \text { anya } & \text { mongala } & \text { dibuq } & \text { moq } & \text { arino } & \text { lan } \\ \text { 3rdsg.nonhuman } & \text { fill } & 3^{\text {rd }} \text {.sg.masc } & \text { very } & \text { short } & \text { and } & \text { person } & \text { numerous }\end{array}$ 3rdsg.nonhtman fil zort and person humerous

$\begin{array}{lllllll}\begin{array}{l}\text { pojoq } \\ \text { and.FOC }\end{array} & \begin{array}{l}\text { mongala } \\ \text { very }\end{array} & \begin{array}{l}\text { baqu } \\ \text { many }\end{array} & \begin{array}{l}\text { puhukung } \\ \text { gather.together }\end{array} & \begin{array}{l}\text { Yesus } \\ \text { Jesus }\end{array} & \begin{array}{l}\text { ko } \\ \text { result }\end{array} & \begin{array}{l}\text { Jakeus } \\ \text { Zaccheus }\end{array} \\ \text { nyian } & \text { halop } & \text { mang } & \text { Yesus. } & & & \\ \text { not } & \text { able } & \text { see } & \text { Jesus. } & & \end{array}$

'But he was very short, and the crowd around Jesus was so numerous that Zaccheus could not see Jesus.' Luke 19:3, LT

The subjective, scalar implicature of the use of the term dibuq is exemplified here, in parallel with cutang. In this case, a crowd of people provides a context, and Zaccheus is short relative to the average height of the people in the crowd.

In addition, some of these terms can be applied both spatially and temporally (lokin, lunhang, nyokamat, nyopotan). Based on the current status of locational and temporal information in Hobongan (Perkins 2017), it is hypothesized that the spatial information is primary and that the temporal information is a semantic extension of the spatial aspect of the conceptualization, but further research is needed.

\section{3b. Topological qualities}

Hobongan has several terms that are used as estimates of topological qualities, a sort of meta-measurement of topological characteristics: cang iq (not even a little); daan (too much); kol koq (smallness); kolongeang (length); kosiroq (strength); tokung (completely); topiut (completely; difference from tokung not known); uso (length, usually short). The phrasal terms in this category are often used as idiomatic expressions. Only one of them is idiomatically negative; otherwise, negatives must be constructed with the use of a negative term, nyian (not or no). There are also semantic minimal pairs that access scalar implicatures, analogous to the semantic minimal pairs of qualities or actions, but with fewer distinctions relative 
to the spatial dimensions. There is one distinction for magnitude along any one axis (kolongeang and uso). The other minimal pair is relative to a conceptualized estimate of amount, one being phrasal and other not (cang iq and daan).

$\begin{array}{llllllll}\text { Moq } & \text { kokosiroq } & \text { ko } & \text { poqo } & \text { pongalan } & \text { anya } & \text { nong } & \text { Akeq Tingai } \\ \text { And } & \text { increasingly.strong } & \text { result } & \text { also } & \text { faith } & 3^{\text {rd.sg.masc }} & \text { LOC } & \text { God }\end{array}$

'And he grew stronger in his dependence on God.' Luke 1:80, LT

$\begin{array}{llllllll}\text { Kokoq } & \text { no } & \text { ko } & \text { borin } & \text { dimo } & \text { ko } & \text { manuq } & \text { pit? } \\ \text { Equal.size } & \text { which } & \text { result } & \text { price } & \text { five } & \text { INTERROG } & \text { bird } & \text { little.birds }\end{array}$

'Aren't five little birds sold for two small (coins)?' Luke 12:6, LT

These examples are both used with prefixes, which are ko- and ko-; this particular syllable has many meanings in Hobongan. In the first example, it indicates that the strength is increasing or intensifying; in the second example, it ind cates that the smallness is carried across two items of equal size, that together are small. The pragmatic emphasis in the second sentence is on how inexpensive the birds are.

\subsection{Temperature}

Temperature terms are broadly divided into individual perceptions of temperature and some conceptualized consensus about what constitutes a warm or cool temperature in the environment. The terms are as follows: dingom (cool, as of temperature); daharang (hot, what a person feels); korarom (cold, what a person feels)/darom (a variant form); latot (hot, of an object or temperature; lit., be in the sun); ngoringom (to cool off in a cool place); ngosingom (cool off); nyahatai (really hot); nyiru (warm oneself by a fire); singom (cold, of an object); tik (hottest part of the day).

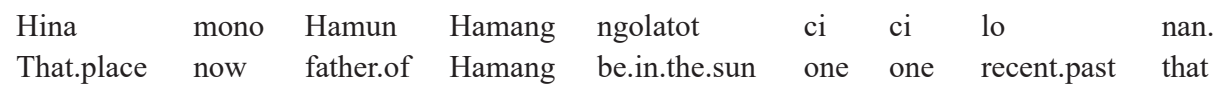

'There now Hamun Hamang put himself alone in the sun.' HH

\begin{tabular}{|c|c|c|c|c|c|}
\hline Moq & hibo & mon & a & mang & kiu \\
\hline & & & one & see & \\
\hline
\end{tabular}

$\begin{array}{lllllll}\text { ngolonge } & \text { joq } & \text { ho } & \text { tobanon } & \text { naqan } & \text { a } & \text { toqo } \\ \text { sprout.new.leaves } & \text { FOC } & 3^{\text {rd }} \text {.sg.nonhuman } & \text { sign } & \text { so.that } & \text { one } & \text { know }\end{array}$

$\begin{array}{llllllll}\text { ihan } & \text { singom } & \text { lua } & \text { nyopo } & \text { moq } & \text { ihan } & \text { latot beong } & \text { abiq. } \\ \text { season } & \text { cold } & \text { past } & \text { change } & \text { and } & \text { season } & \text { hot } & \text { future } \\ \text { arrive. }\end{array}$

'Whenever one sees trees sprouting new leaves, it is a sign so that you know that the cold season is past and the hot season is coming.' Luke 21:30, LT 
These examples include instances of singom and latot being used both in isolation and with a prefix, in one case, ngo-, which is a prefix that indicates that a term with descriptive semantic content is used as an adjective. In neither case do the terms refer to people, but to things or to the environment. Note that heat is equated with being in the sun.

\subsection{Temporality}

Time is a complex phenomenon and can be conceptualized into a number of different domains, including time, duration, sequence, and rate. Hobongan measurement terms cover each of the aforementioned domains: but (suddenly); cop (until); de (before, in time or in a narrative); deen (finished in a single day); kolenga (lateness); kolokahan (quickness); koringu (lost temporarily); kunot (slowly and steadily); lapon (later, after); lokin (close in time or distance); loon (yesterday, finished recently); lua (completely, after, completed aspect); lucit (immediately following); luhang (middle of time or space); lusap (tomorrow); malum (when, temporal relativizer); maum (old, rough); meteq (occasionally); milang (every time, every place); mon (whenever); nahala (quickly, without delay); nobolo (to arrive quickly, to rise into the air); nobuku (archaic way to count days, lit. to wrap around); noon (question word for time); nyokamat (to do something small or for a short time); nyopotan (to do something big or for a long time); nyuap (morning); usung (middle of an activity).

There are phrasal options: koqung maam (the middle of the night; koqun, round object); lohaq na (day after, in narrative); nyiqun papat (to run away quickly; nyiqun: light weight); puq utung utung (the entire time); sa lua ini (distant future; sa: toward); sa mokoq poqo (sometime in the future).

"Ni cien de heo ko deen," keo Hamun Hamang.

That good before voice $2^{\text {nd }}$.sg/result finished.same.day you.spoke father.of Hamang

“"That was good before you said it was done," said Hamun Hamang.' HH

In this example of de and deen, and in the previous example in which lua occurred, several types of temporal information are shown. De indicates any kind of precession in a sequence, and deen indicates the completion of a sequence and includes time as such, with the limit being a day. Lua is used both syntactically as a general past marker, as in the examples above, but it can also be used to indicate completion in some contexts.

\subsection{Miscellaneous leftovers}

In this category are measurement terms that did not seem to be adequately covered in previous categories. The terms are as follows: coan (overfed); jaala 
(overstuffed); kocahit (heavy rain); kocalok (sound sleep); korongan (low stool); kotomaha (hardest wood); lomueq (overflow); lota (small amount of rice (now archaic)); maasut (overflow); mahakat (overflow of liquid); mahatoq (exactly right, omnipotent); ngolalak (talk all of the time); ngoruok (sprout quickly); ngotop (small bite, nibble); nguti (get up suddenly); nobolo (arrive quickly); nopungam (heaped up in abundance); noranga (have a fever for a long time); pating (small branches of a tree); saga (unit of measure for gold); taqang (unit of measure for a tawak, a type of gong)

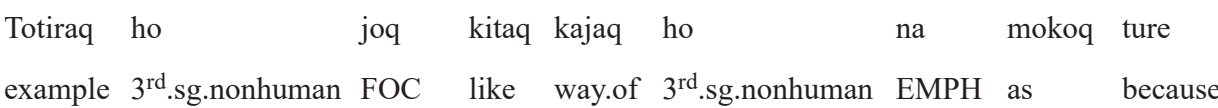

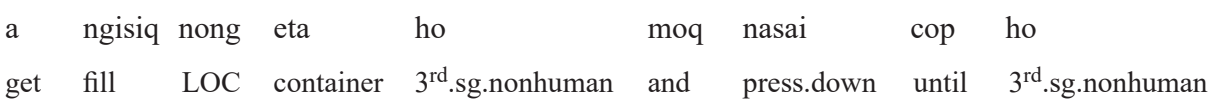

lomueq naq eta ho deen.

overflow origin container $3^{\text {rd }}$.sg.nonhuman finished.same.day

'The illustration is like what one puts in a container and presses down to the point that it overflows from its container.' Luke 6:38, LT

This example was chosen in order to show one of the main patterns in this broad category of terms: the commonness of too much or too little of something as part of the semantic content. In this case, a container limits the contents, and the material beyond the volume of the container is lomueq: too much, so that the container overflows. Less pragmatic estimation is required for many of these terms because more objective limits at available, like the volume of a container or the volume of a stomach or mouth.

\section{Discussion}

The material presented here includes several patterns that recur in Hobongan measurement and quantification.

\subsection{Stevens' Progression vs. Hobongan Selection}

Stevens (1957) treats the series from counting to ordinals to intervals to ratios as a progression, with counting being the least informative for measurements, because the least constrained, and ratios being the most informative for measurements, because the most constrained. Yet in Hobongan, the situation is different from Stevens' progression. With regard especially to the use of the original number terms as article-like words, there is a non-arbitrary zero (an absence is not marked), 
as in a ratio scale, but the intervals between measurements is not consistent, as in ordinals, because individual speakers make the estimates based on context and individual preference. Hobongan mixes characteristics of the scales rather than having a progression.

Hobongan temperature terms and many of the terms in the miscellaneous category and all of the terms in the topological category are ordinal in nature because they rely on scalar implicatures, lack a non-arbitrary zero, and lack fixed intervals. However, there are two units of measurement, for gold (saga) and for gongs (taqang), ${ }^{2}$ that can be used as interval scales or as ratio scales when required. When used as interval scales, the Hobongan combine these terms with the full complement of counting terms that have been imported into the language, and the combination of quantification and units of measurement provides the standard intervals. In other words, there is no progression from one type of measurement and quantification to another. The choice of what scale to use is based on speakers' pragmatic understandings of contexts, cultural knowledge about what must be measured precisely vs. what can be estimated, and sometimes on materials (gold or gongs). Hobongan speakers can select and combine semantic elements to achieve different types of measurement. None are more or less informative than others, simply different and selected because of contextual requirements or pragmatic implicatures.

Time is also treated ordinally in Hobongan, with arbitrary zeros and no fixed relationships between and among measured phenomena. It might be suggested that night and day provide a non-arbitrary zero for time, or a fixed interval, but either night or day would have to be chosen as the non-arbitrary starting point for time, and that choice makes the measurements and estimates about temporal information inherently arbitrary. Further, it might be suggested that semantic content like 'middle' in the middle of the night might indicate a fixed interval measurement, but in practice, such terms are used to indicate a subjective experience; for example, someone who went to bed and slept soundly starting at $6 \mathrm{p} . \mathrm{m}$. might feel like 9 p.m. is the middle of the night and talk about 9 p.m. as if it is the middle of the night, even though that specific time is not the middle of the darkness at the equator. Deen is an interesting term because it relies on a potentially fixed interval, a day, but even in this case, duration of a day can be varied based on what speakers want to communicate. A day might be just the daylight, and not the night, or might be a full, 24-hour period. There are also conceptualizations of days relative to specific activities; when people are building a boat, they typically work for several hours and then stop, and that could be conceptualized as a boat-day, and deen could be used felicitously.

${ }^{2}$ In Hobongan jurisprudence, people are often fined in gongs for various infractions. It is therefore important to be able to quantify gongs' sizes and weights precisely in order to ensure that justice has been done and that the penalties have not been either unjustly severe or unjustly lenient. 


\subsection{Plexity and Subjectivity}

Plexity items present fewer complications to the understanding of measurement in language, and specifically in Hobongan, but plexity does shift what can be counted or measured, depending on speakers' conceptualizations of situational contexts. Having ways to shift countability from within and across domains indicates a Hobongan understanding that subjective estimation is foregrounded over numbering for quantification for numbering and measurement. What is measured must be chosen for measurement, and for type of measurement, which indicates an inherent skepticism of the possibility of objectivity in measurement.

\subsection{Whose Embodiment?}

Many of the topological terms are embodied in some way, and not always based on a human body. Terms such as dopo (arm's length) are topological because they vary according to the person and also because there is a concept of an average, adult human's 'arm's length'. Children can use these terms, which provides the evidence of magnitude neutrality required to be topological, and the people involved make the necessary adjustment in scale given a child's arm.

However, plants can also provide conceptual material for measurements, relying on a default understanding of the plants. For example, kotolusiq can vary depending on the species of fruit, but there is also a conceptualization of an average ratio of pit-to-flesh that informs the uses of the term. Determining that ratio, and what fruits might be the basic-category items that contribute to that ratio, are good candidates for empirical research in the future. In addition, when plants are providing embodiment concepts, it would be worthwhile to consider the ways in which this might challenge or reinforce current understandings of embodiment — what is it like to be a plant?

One major difference between embodiments provided by people or plants is that embodied measurements based on people provide typical orientations for people, and plants do not. People canonically stand; this is confirmed by an idiom about laziness:

\begin{tabular}{|c|c|c|c|c|c|c|}
\hline $\begin{array}{l}\text { do } \\
3^{\text {rd }} . \mathrm{pl}\end{array}$ & $\begin{array}{l}\text { bareq } \\
\text { different }\end{array}$ & $\begin{array}{l}\text { ure } \\
\text { do }\end{array}$ & $\begin{array}{l}\text { joq } \\
\text { FOC }\end{array}$ & $\begin{array}{l}\text { hiro } \\
3^{\text {rd }} \cdot \mathrm{pl}\end{array}$ & $\begin{array}{l}\text { kotoselat } \\
\text { slip }\end{array}$ & $\begin{array}{l}\text { joq } \\
\text { FOC }\end{array}$ \\
\hline & joq & & & & & \\
\hline
\end{tabular}

'They slip and fall with their legs already stretched out.'

This example shows the assumption of a standing posture by noting a deviation from that posture. It is also worth noting that sitting with legs straight out is a canonical sitting posture. The idiom relies on a lack of transition between standing and sitting to indicate laziness. 
Both fingers and arms are conceptualized as extended when used as the standards of measurement: legs straight for standing, or fingers long. Humans can also provide a $\mathrm{y}$-axis orientation relative to a ground-level $\mathrm{x}$-axis in order to provide semantic content for terms indicating depth or shallowness.

Plants lack a canonical orientation; a segment of bamboo can be used as a unit of measure for other materials, regardless of whether they are oriented as might be expected of a segment of bamboo when part of a living plant; this backgrounding of the orientation of living plants might indicate that the Hobongan conceptualize plants in the ways in which the plants are useful to them rather than as entities unto themselves.

\section{Conclusions and directions for future research}

In Hobongan, there is not an emphasis on what English speakers would consider objective measurements, and there is not a progression from ordinal to interval to ratio scales. Instead, all of the measurement terms can be used subjectively, depending on speakers' understandings of contexts, and objective measurements require combinations of quantificational and measurement terms. The Hobongan appear to have a different understanding of the relationships between measurements and quantification. Measurement in the form of estimation is required; quantification in the more objective sense is usually optional or used only in specific domains (gold, gongs).

That languages, including Hobongan, have ways to shift countability from within and across domains indicates a Hobongan understanding that for numbering and measurement, subjectivity is foregrounded; what is measured must be chosen for measurement, and for type of measurement, which is honest, even if not overtly available to consciousness, about the choices that are being made and that can be made.

Hobongan measuring and quantification suggest a number of directions for future research. One is to investigate in more detail the Hobongan philosophy of measurement and counting. The material included here points to some interesting possibilities. The main possibility is that measurement is required and quantification is optional. There are also two kinds of progressions that can interact and intersect to determine and explain how these terms are used. The first progression exists in the terms, from the broadest estimates provided by the basic ordinal numbers, to narrower estimates based on contexts (how long a day is), to the narrowest quantifications that combine counting and measurement terms. The second progression exists in cultural pragmatics and governs the making of decisions about what to quantify; gold and gongs must usually be quantified, but time usually does not need to be quantified. The uses of gold and gongs that the Hobongan quantify were both introduced by outsiders at some point in Hobongan history. Gold does 
not need to be quantified when used as a material, only when used for trade; time is usually not quantified but might need to be quantified when determine people's ages for official forms. The Hobongan recognize the relevant situations and make decisions about quantification based on the situations, with estimation being more important and more frequent than quantification.

Another direction for future research is to sort out in Indo-European languages how ideas about objectivity and scientific-ness are represented in the language itself or taught to people in educational contexts. A study on the interactions between the cultural ascendancy of science and mathematics and what is available in language could illuminate the ways in which people understand, or fail to understand, ideas that are culturally important. Everyday Hobongan requires estimation; English scientific discourse requires quantification. Exploring that information and those distinctions could then be compared to other such studies on additional languages, in order to develop a linguistic typology of measurement and quantification in the world's languages and in uses of the world's languages.

\section{References}

Czaykowska-Higgins, E. 2009. "Research Models, Community Engagement, and Linguistic Fieldwork: Reflections on Working with Canadian Indigeous Communities.” Language Documentation and Conservation 3:1. 15-50.

Dimmendaal, G.J. 2001. "Places and People: Field Sites and Informants." In: Newman, P. and M. Ratliff (eds.). Linguistic Fieldwork. Cambridge: Cambridge University Press. 55-75.

Hammarström, H., R. Forkel, and M. Haspelmath. 2017. Glottolog. http://www.glottolog.org/resource/languoid/id/hovo1239.

Kranz, D., D. Luce, P. Suppes, and A. Tversky. 1971. Foundations of Measurement. vol. 1. Additive and Polynomial Representations. New York: Academic Press.

Perkins, M. 2017. “An Introduction to Nexus Theory.” Paper presented at the Cognitive Linguistics in Wrocław Conference, 2-3 December. https://drive.google.com/file/d/1Rc5LwoYPRZw0vL kdzxSy8U9ZwD92ukzd/view.

Perkins, M. 2017. "Toward a Typology of Ranking Elements of Narrative Discourse in Languages and Cultures: A Cross-Linguistic Survey." International Journal of Literary Linguistics 6:1. http://www.ijll.uni-mainz.de/index.php/ijll/article/view/101.

Sellato, B. and P.G. Sercombe. 2007. "Introduction: Borneo, Hunter-Gatherers, and Change." In: Sercombe, P.G. and B. Sellato (eds.). Beyond the Green Myth: Borneo's Hunter-Gatherers in the Twenty-First Century. Copenhagen: NIAS Press. 1-49.

Simons, G.F. and C.D. Fennig. 2017. Ethnologue. http://www.ethnologue.com/language/hov.

Solt, S. 2016. "On Measurement and Quantification: The Case of Most and More than Half. Language 92:1. 65-100.

Stevens, S.S. 1957. "On the Psychophysical Law.” Psychological Review 64:3. 153-181.

Talmy, L. 2000. "The Relation of Grammar to Cognition.” In: idem (eds.). Toward a Cognitive Semantics. vol 1. Concept Structuring Systems. Cambridge: MIT Press. 21-96.

Van Lier, E. 2016. "Lexical Flexibility in Oceanic Languages." Linguistic Typology 20:2. 197-232. 